\title{
Hernia surgery and contamination: biological mesh and nothing else?
}

\author{
M. Miserez • R. J. Fitzgibbons Jr. • V. Schumpelick
}

Received: 5 January 2013/Accepted: 7 January 2013/Published online: 17 January 2013

(C) Springer-Verlag France 2013

\begin{abstract}
Although the use of synthetic meshes has dramatically decreased the recurrence rate after the treatment of hernias of the abdominal wall, we know that their use in a setting of contamination or in certain locations can lead to specific complications such as mesh infection or erosion. To overcome these problems, a completely new generation of so-called remodelling biological scaffolds from human or animal origin or even new synthetic constructs have been promoted in recent years. Despite the fact that these
\end{abstract}

materials might be useful in certain conditions, the evidence from high-quality studies, preferably with an adequate control group, is low. This issue of Hernia bundles 11 papers on this intriguing subject, together with a critical invited comment by Dr. Agneta Montgomery. In this way, the editors of Hernia want to offer their readers a balanced state-of-the-art picture on this controversial topic anno 2013.

M. Miserez $(\bowtie)$

Leuven, Belgium

e-mail: marc.miserez@uzleuven.be

R. J. Fitzgibbons Jr.

Omaha, USA

V. Schumpelick

Hamburg, Germany 